\title{
DECAPACITATION AND RECAPACITATION OF RABBIT SPERMATOZOA TREATED WITH MEMBRANE VESICLES FROM SEMINAL PLASMA
}

\author{
B. K. DAVIS \\ The Worcester Foundation for Experimental Biology, Shrewsbury, \\ Massachusetts 01545, U.S.A.
}

(Received 11th May 1974)

'Two classes of membrane vesicles have been isolated from rabbit seminal plasma (Davis, 1973a, b). The less dense vesicle fraction (Fr. II) was shown to inhibit fertilization at concentrations between 20 and $72 \mu \mathrm{g}$ protein $/ \mathrm{ml}$, after oviducal insemination of does with treated spermatozoa capacitated in utero (Davis, 1971). When these sperm cells were exposed to the dense vesicle fraction (Fr. I), at concentrations up to $160 \mu \mathrm{g}$ protein/ml, their fertilizing capacity was unaffected. Both vesicle fractions, however, blocked fertilization of rat eggs in vitro at relatively low concentrations (Davis \& Niwa, 1974). This result demonstrated that both classes of vesicles have decapacitation activity.

The present experiments were undertaken to establish if Fr. I can decapacitate rabbit spermatozoa at higher concentrations than those used previously. A second objective was to show that spermatozoa decapacitated by treatment with these vesicle fractions can recover their ability to fertilize. Sperm decapacitation by seminal plasma is reversible (Chang, 1957) and, consequently, the inhibitory action of active fractions from seminal plasma would also be expected to be reversible.

Semen was obtained from fertile bucks with an artificial vagina and sedimented in a desk-top centrifuge at $1000 \mathrm{~g}$ for $30 \mathrm{~min}$. The seminal plasma ( 1 to $2 \mathrm{ml}$ ) was aspirated and layered on a discontinuous density gradient with $14 \mathrm{ml}$ of $20 \%$ (w/v), $12 \mathrm{ml}$ of $40 \%$ and $5 \mathrm{ml}$ of $60 \%$ sucrose zones in KrebsRinger phosphate buffer, $\mathrm{pH} 7 \cdot 0$, and fractionated by ultracentrifugation as described previously (Davis, 1973b). Isolated fractions containing membrane vesicles were then resedimented and dialysed against Hanks solution (Difco) supplemented with $100 \mu \mathrm{g} \mathrm{Ca}{ }^{++} / \mathrm{ml}$. The effect of the seminal plasma vesicle fractions on sperm fertilizing capacity was determined from the fertilization rates achieved following insemination with treated and control sperm cell preparations. Capacitated sperm cells used in this assay were obtained by flushing the uterus of a doe with $4 \mathrm{ml}$ Hanks solution containing $150 \mu \mathrm{g}$ $\mathrm{Ca}^{++} / \mathrm{ml}$, usually 12 to $13 \mathrm{hr}$ after mating. The recovered sperm cell suspension was subsequently used for oviducal insemination of does that had been induced to ovulate with 90 i.u. HCG about $2 \mathrm{hr}$ before sperm deposition. These does were killed on the following day to permit egg recovery (see Davis, 1971).

The fertilization rates obtained following insemination of does, about $2 \mathrm{hr}$ 


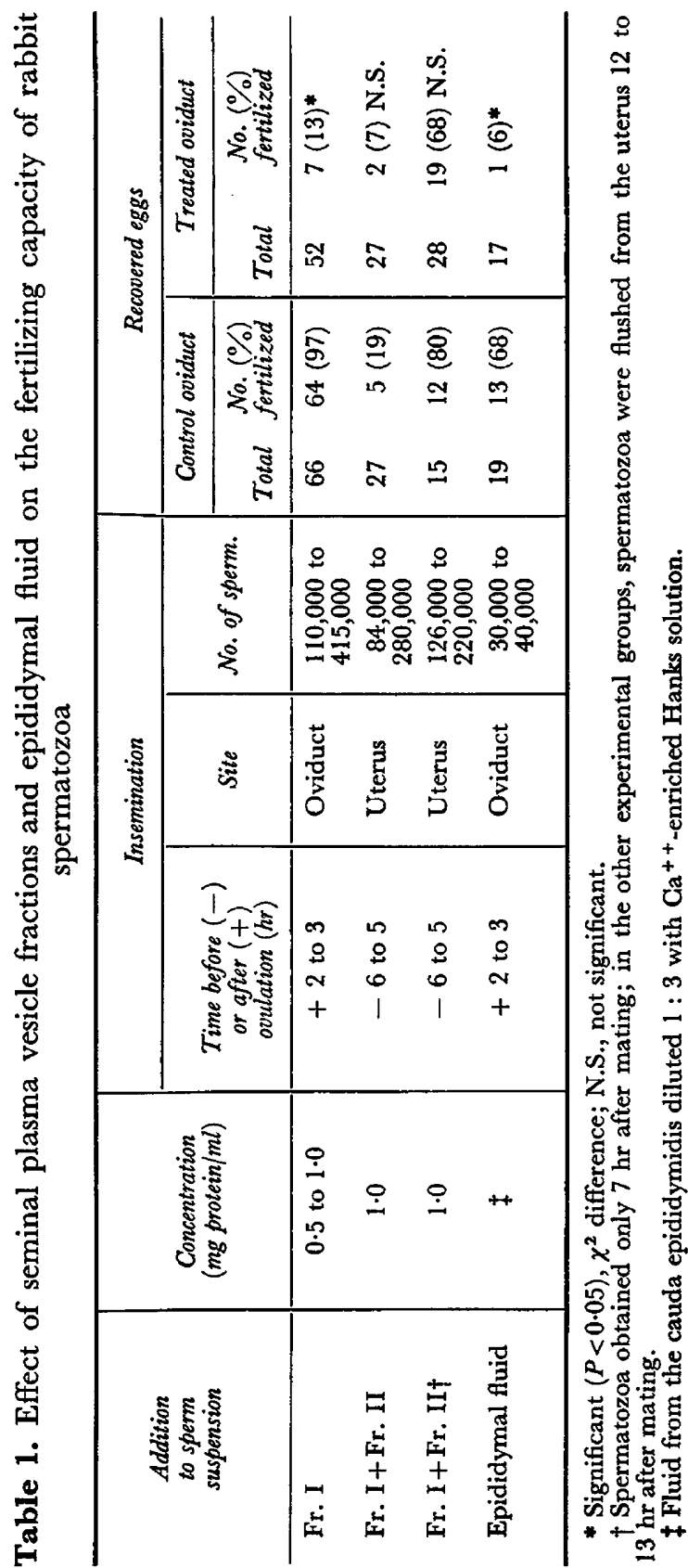


PLATE 1

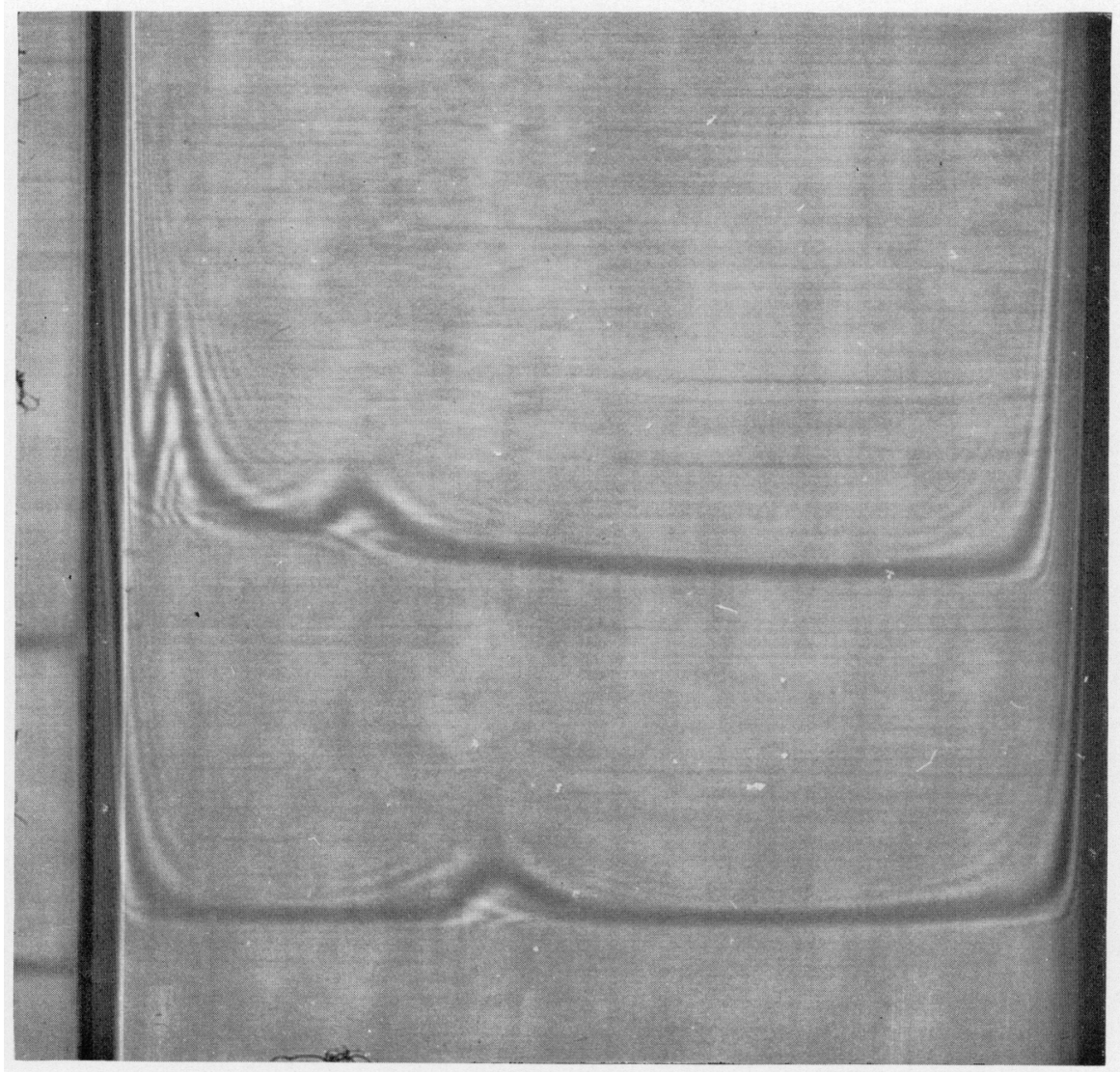

Schlieren patterns of fluid from rabbit cauda epididymidis (lower), diluted fourfold with modified Hanks solution, and seminal plasma (upper) after centrifugation at $81,310 \mathrm{~g}$ for $3 \mathrm{~min}$ at $20^{\circ} \mathrm{C}$ in an $\mathrm{An} \mathrm{D}$ rotor with standard and wedge $4^{\circ}$ sector cells; bar angle $65^{\circ}$.

(Facing p. 242) 
after ovulation, revealed that 0.5 to $1 \mathrm{mg}$ Fr. I/ml impaired the fertilization capacity of rabbit spermatozoa (Table 1). To discount the possible presence of Fr. II vesicles, control spermatozoa were suspended in dialysed pooled fractions from the $20 \%$ and $40 \%$ sucrose interfaces, which corresponded to the presumptive Fr. II region in the density gradients employed to isolate Fr. I (Davis, 1973b). As shown in Table 1, 97\% of the recovered eggs $(64 / 66)$ were fertilized in oviducts in which control spermatozoa were deposited, whereas only $13 \%$ of eggs $(7 / 52)$ were fertilized with spermatozoa exposed to 0.5 to $1.0 \mathrm{mg}$ protein $/ \mathrm{ml} \mathrm{Fr}$. I; six of the seven eggs fertilized by spermatozoa treated with Fr. I were from a single doe. To minimize the effects of variation between animals on the fertilization rates observed, control spermatozoa were placed in the left oviduct and treated spermatozoa in the right oviduct. Variation from this source was, however, relatively small in these experiments.

The results given in Table 1 also demonstrate that epididymal fluid inhibited the fertilizing ability of rabbit spermatozoa capacitated in utero. Epididymal fluid used in this experiment was flushed from an excised cauda epididymidis of a fertile buck with $0.5 \mathrm{ml}$ modified Hanks solution and sedimented at $1000 \mathrm{~g}$ for $30 \mathrm{~min}$ to remove sperm cells.

The decapacitation activity of epididymal fluid (Weinman \& Williams, 1964) and the need to capacitate epididymal spermatozoa before fertilization (Yanagimachi \& Chang, 1963; Toyoda, Yokoyama \& Hosi, 1971) can evidently be explained by the high content of Fr. I-type vesicles in the epididymis. The presence of these rapidly sedimenting vesicle components in rabbit epididymal fluid and seminal plasma may be established from the Schlieren patterns developed during centrifugation in an analytical ultracentrifuge. As can be seen in Plate 1, seminal plasma formed two boundaries corresponding to Fr. I and Fr. II (Davis, 1971) that were calculated to have sedimentation coefficients of $156 \mathrm{~S}$ and $57 \mathrm{~S}$, respectively. Epididymal fluid (diluted fourfold with modified Hanks solution) displayed only one boundary that sedimented at approximately $224 \mathrm{~S}$ which was close to the sedimentation coefficient of $221 \mathrm{~S}$ obtained for Fr. I in buffer. The retarded sedimentation of Fr. I (156S versus 221S) in seminal plasma compared with that in buffer can be attributed to the higher viscosity of the former fluid.

The recovery of fertilizing capacity by decapacitated spermatozoa was studied with sperm cells flushed from the uterus of does that had been mated either 7 or $13 \mathrm{hr}$ before autopsy. When spermatozoa capacitated in utero, obtained $7 \mathrm{hr}$ after mating, were decapacitated with a vesicle suspension containing $1.0 \mathrm{mg}$ protein $/ \mathrm{ml}(0.5 \mathrm{mg}$ protein $/ \mathrm{ml}$ of Fr. I and Fr. II $)$ and were then deposited into the uterus approximately $6 \mathrm{hr}$ before ovulation, it was possible to demonstrate sperm recapacitation. Table 1 shows that $68 \%(19 / 28)$ fertilization was achieved in eggs from oviducts receiving spermatozoa exposed to seminal plasma vesicle-containing fractions (Fr. I + Fr. II) and this was not significantly lower than the $80 \%(12 / 15)$ fertilization rate obtained with untreated sperm cells. Spermatozoa obtained $13 \mathrm{hr}$ after mating displayed poor fertilization capacity when they were inseminated $6 \mathrm{hr}$ before ovulation (Table 1). Their relatively advanced age (19 to $20 \mathrm{hr}$ ) at the time of ovulation could have been responsible. Insemination into the uterus, rather than into the ovi- 
duct, was employed for recapacitation of spermatozoa in the present experiments because capacitation seems to proceed more efficiently with the former method (Adams \& Chang, 1962).

The fact that seminal plasma from intact and vasectomized bucks and epididymal fluid can decapacitate spermatozoa is consistent with both types of vesicles having inhibitory activity. Sperm decapacitation can perhaps be achieved in different ways, since two superficially different factors have been shown to induce this state. Both active factors were identified as vesicles (Davis, $1973 \mathrm{~b}$ ), however, and this may give some clue to their mechanism of action.

The skilful assistance of $\mathrm{Mr}$ John Whitney is gratefully acknowledged. Financial support was received from N.I.H. Contract No. 1-HD-3-2781.

\section{REFERENCES}

Adams, C. E. \& Chang, M. C. (1962) Capacitation of rabbit spermatozoa in the Fallopian tube and in the uterus. 7. exp. Zool. 151, 159.

Chang, M. C. (1957) A detrimental effect of seminal plasma on the fertilizing capacity of sperm. Nature, Lond. 179, 258.

Davis, B. K. (1971) Macromolecular inhibitor of fertilization in rabbit seminal plasma. Proc. natn. Acad. Sci. U.S.A. 68, 951.

DAvis, B. K. (1973a) Isolation and characterization of rabbit decapacitation factor. 7. Cell Biol. 59, 71a.

Davis, B. K. (1973b) Occurrence of vesicles in rabbit seminal plasma. Experientia, 29, 1484.

DAvis, B. K. \& NIwA, K. (1974) Inhibition of mammalian fertilization in vitro by membrane vesicles from seminal plasma. Proc. Soc. exp. Biol. Med. 146, 11.

Toyoda, Y., Yoxoyama, M. \& Hosi, T. (1971) Studies on the fertilization of mouse eggs in vitro. I. In vitro fertilization of eggs by fresh epididymal sperm. Jap. 7. Anim. Reprod. 16, 147.

Weinman, D. E. \& Williams, W. L. (1964) Mechanism of capacitation of rabbit spermatozoa. Nature, Lond. 203, 423.

Yanagimachi, R. \& Chang, M. C. (1963) Fertilization of hamster eggs in vitro. Nature, Lond. 200, 281. 